Article

\title{
Understanding the Professional Practice of Teachers of Chinese as an Additional Language through the Lens of Teacher Agency
}

\author{
Min Bao ${ }^{1,2}$, Wei Ren ${ }^{3, *}$ and Danping Wang ${ }^{4}$ \\ 1 Institute of Linguistics, Shanghai International Studies University, Shanghai 200083, China; ellen@seu.edu.cn \\ 2 School of Foreign Languages, Southeast University, Nanjing 211189, China \\ 3 School of Foreign Languages, Beihang University, Beijing 100191, China \\ 4 School of Cultures, Languages and Linguistics, The University of Auckland, Auckland 1142, New Zealand; \\ danping.wang@auckland.ac.nz \\ * Correspondence: weiren@buaa.edu.cn
}

Received: 28 July 2020; Accepted: 5 September 2020; Published: 11 September 2020

check for updates

\begin{abstract}
Teacher agency plays a key role in sustaining the professional practice of language teachers, including teachers of Chinese as an additional language (CAL), to ensure sustainable multilingualism in universities. This paper reports on an exploratory study that examined five CAL teachers' experiences of using teaching materials in a leading Belarussian university. Drawing on theorization about teacher agency, the analysis of the participants' experiences helped to reveal the manifestations of teacher agency in their engagement with teaching materials in their teaching, which emerged from interactions between individual aspirations and contextual conditions. In particular, the findings highlight that three factors, namely teachers' beliefs, teacher identity, and relationships within their community, play significant roles in mediating the participants' exercise of agency in using teaching materials. The findings not only contribute to the conceptualization of teacher agency, but suggest that pedagogical content knowledge (PCK) and materials development of CAL teachers should be emphasized in supporting effective teaching, so that they can achieve sustainable professional practice to ensure sustainable multilingualism in universities.
\end{abstract}

Keywords: teacher agency; Chinese as an additional language (CAL); Chinese teaching and learning; agency orientation; Chinese textbooks

\section{Introduction}

Teachers are at the heart of language education and language policy research, playing a critical role in implementing policy initiatives and delivering curriculum reforms [1,2]. Teacher agency, i.e., the initiatives and autonomy of teachers, has been a focus of recent language teacher education research. When particular language education policies are launched, language teachers are crucial agents who can act either actively or passively in implementing them at the micro level, i.e., classrooms [3-5]. In other words, teachers can display different reactions towards particular policy initiatives, including appropriation, implementation, and resistance, which may contribute to the failure or success of that policy implementation. Their efforts to update themselves with current pedagogical and subject content knowledge are indicative of their agency of operation, and can be instrumental in ensuring that curriculum reforms are meaningful and effectively enhance students' learning. In other words, teacher agency plays a critical role in sustaining teachers' effective practice and their efforts to develop themselves for implementing effective practice.

Recent studies have explored the role and phenomenon of language teacher agency in a variety of contexts [6,7]. These studies have examined teachers' agency in their negotiations of pedagogical 
practice [8], professional identity [9], pedagogical expertise [10], and emotions [11]. However, most of these studies have focused on English language teachers, who teach a language of global significance that is widely associated with power, wealth, and global social mobility [12,13]. Few studies have explored the role of teacher agency in the professional practices of language teachers who teach languages other than English (LOTEs), such as CAL. We believe that the teaching and learning of CAL, along with (LOTEs), can contribute to sustainable multilingualism in universities [14-16], and it is therefore important for research to focus on CAL teachers' professional experiences. This study sets out to do this, using agency as a lens.

In the last decade, the Chinese language has been on the rise and is on the way to becoming a global language, taught at different levels in an increasing number of countries [17]. Research has also begun to explore how CAL teacher agency may be facilitated and constrained by the political language planning context, for example in post-1997 Hong Kong [18]. It should be noted that the rise of Chinese as an international language has caused a significant outflow of CAL teachers from China to a variety of educational contexts, such as the United States and Russia [19]. Many of these teachers are ill-prepared for teaching language learners with diverse learning needs in contexts different from their own, especially in terms of their use of textbooks in contextualized situations.

Textbooks for international readers studying Chinese as a foreign language (CFL) have proliferated over the last three decades [17]. Since a peak period at the beginning of the 21st century, Chinese textbook publication numbered 17,800 volumes by the year 2017 [20,21]. However, a lack of suitable textbooks specially designed for particular overseas contexts is a significant issue [22]. Studies on CAL textbooks have explored a variety of topics such as cultural themes $[23,24]$, ideology and national identity [17], and organization of topics [25]. However, only a small amount of research has investigated the interaction between teachers and textbooks through the lens of agency. Given that pedagogical materials are important resources for language teachers, it is vital for us to explore how they are able to adapt and develop context-appropriate materials for teaching.

Therefore, this paper draws on teacher agency as a theoretical lens to interpret CAL teachers' pedagogical efforts in their adaptation of teaching materials in a Belarussian university, a context that has been underrepresented in CAL-related studies to date. In the coming sections, we shall elaborate on our theorization of teacher agency before we present our inquiry.

\section{Theorizing Teacher Agency}

The notion of teacher agency can be theorized in a variety of ways. Eteläpelto et al. [26] identified four major research traditions in theorizing agency, i.e., the social science tradition, the post-structural tradition, the socio-cultural approach, and the identity and life-course approach. In the social science tradition, represented by Giddens [27] and Archer [28,29], the scholars see agentic action as intentional but have opposite views "in other respects, such as in the ontology and relations between the individual and the social" [26] (p. 51). The post-structural tradition uncovers the unofficial and invisible power relations in work communities, and defines agency as "the individual's capacity for self-reflection and self-evaluation related to subjects' experience of the world" [26] (p. 53). The social-cultural approach holds that "the way subjects think, act and learn is always imbued and resourced-and also constrained-by their socio-cultural contexts" [26] (p. 57), while the identity and life-course approach explores individual ways of constructing life courses through choices and actions in relation to what people aspire to be, or their identity commitments.

Within these traditions, agency can be conceptualized "as variable, as capacity, as phenomenon" [30] (p. 29). When it is seen as variable, "agency is often set against structure, where the key question is whether structure or agency is more important in determining or shaping social action" [30] (p. 28). When agency is viewed as capacity, it is something that people as agentic individuals possess. Finally, agency as an emergent phenomenon is seen as something that is achieved by individuals, through the interplay of personal capacities and the resources, affordances, and constraints of the environment by means of which individuals act [30]. 
We adopt the theorization of agency as a phenomenon, in that we aim to examine how the interplay between individual attributes (e.g., capacities, emotions, motivations) and contextual conditions (i.e., affordances and constraints) generates the teacher agency underpinning and sustaining language teachers' effective teaching. Agency was used to help us to understand how language teachers negotiate with contextual conditions in their pursuit of professional goals or pedagogic outcomes [7]. The notion also enables us to see teachers as embodied, agentic human actors who possess a unique life-history with individual experiences and competences [26]. Archer [29] and Billett [31] claimed that individuals' exercise of agency is intertwined with their personal interests, identities, and subjectivities. Emirbayer and Mische [32] further contended that teacher agency is influenced by past experiences and habits, orientations towards the future, and engagement with the present. Eteläpelto et al. [26] emphasized the context-specific nature of teachers' agency and called for studies to examine its manifestations, in order to help teacher educators and educational administrators to better support teachers' exercise of agency for effective teaching [26].

The phenomenon of teacher agency can be observed through language teachers' manifested responses, such as compliance with or resistance to reforms and changes [3,33], which means that teachers are unwilling or reluctant to make the changes. Teachers' lack of willingness to change their practice can reveal the interaction between individual teachers and contextual conditions, such as conflicts between newly introduced curricula and deeply-held teaching beliefs. Vähäsantanen and Eteläpelto [4] further identified three orientations of teacher agency towards reform, i.e., resistance, inconsistent, and approval.

Based on the above discussion, we categorize the manifestation of teacher agency into five different orientations - resistance, appropriation, implementation, approval, and ambivalence-for our inquiry of teachers' engagement with textbooks. Teachers with a resistant orientation are not satisfied with the current textbooks [4]. Appropriation refers to individuals "making something of their own from what they encounter in the social world" [26] (p. 56). It reflects a positive attitude to the situation and their own ability whereas before we only got the negative aspect. Implementation refers to accepting and using textbooks completely or mostly in teaching, no matter whether the teachers agree with, disagree with, or feel bewildered about the textbooks. Teachers with an approving orientation see textbooks as positive and inspirational. They can "see a balanced relationship between their actual sense of their professional selves, their prior experiences and the strategic directions of the reform" [4] (p. 26). Ambivalence refers to hesitation and confusion about textbooks.

This conceptualization of teacher agency helps us to examine the manifestations of the CAL teachers' agency in developing and sustaining their professional practice. Since "the effective use of materials depends on the teacher's understanding of the materials, on the fit with their beliefs, expertise, and experience, and on their ability to adapt the materials to their particular learners" [34] (p. 275), research is needed to deepen our understanding of CAL teachers' efforts to use textbooks in their teaching. With the aim of gaining insight into CAL teacher agency and its contributory factors in teachers' engagement with textbooks, we conducted our inquiry to address the following research question in a Belarussian university:

How did CAL teachers engage with textbooks in teaching, through the lens of teacher agency?

\section{Method}

We conducted this exploratory inquiry in a key state language university in Belarus, which is a strategic partner in China's Belt and Road Initiative. The university itself is the only base in the country for cultivating senior teachers and interpreters, and is the center of foreign language education. The Confucius Institute (CI) in this university was established by Hanban (the Confucius Institute headquarters in Beijing, China) in September 2011, and the Chinese department was founded in March 2018. The inquiry involved five CAL teachers recruited by Hanban for the CI in this university. Table 1 below shows a summary of the participants' demographic backgrounds. 
Table 1. Participants $(n=5)$.

\begin{tabular}{|c|c|c|c|c|c|c|}
\hline Teacher & Gender & Age & $\begin{array}{l}\text { Educational } \\
\text { Background }\end{array}$ & Courses & Textbooks & Students \\
\hline Zhang & Male & 26 & $\begin{array}{c}\text { Chinese Language \& } \\
\text { Literature (Bachelor) } \\
\text { International Chinese } \\
\text { language education } \\
\text { (Master) }\end{array}$ & $\begin{array}{l}\text { Integrated } \\
\text { Chinese }\end{array}$ & $\begin{array}{c}\text { New Practical } \\
\text { Chinese Reader } \\
\text { (Books I, II, and III) }\end{array}$ & $\begin{array}{l}\text { Chinese } \\
\text { majors }\end{array}$ \\
\hline $\mathrm{Li}$ & Female & 26 & $\begin{array}{l}\text { Russian Language } \\
\text { (Bachelor) } \\
\text { Research in Russian } \\
\text { Countries (Master) }\end{array}$ & $\begin{array}{l}\text { Chinese } \\
\text { intensive } \\
\text { reading }\end{array}$ & $\begin{array}{l}\text { New Practical } \\
\text { Chinese Reader } \\
\text { (Book III) }\end{array}$ & $\begin{array}{c}\text { Non-Chinese } \\
\text { majors }\end{array}$ \\
\hline $\mathrm{Wu}$ & Male & 28 & $\begin{array}{c}\text { Russian Language } \\
\text { (Bachelor) } \\
\text { International Chinese } \\
\text { Language Education } \\
\text { (Master) }\end{array}$ & $\begin{array}{l}\text { Integrated } \\
\text { Chinese }\end{array}$ & $\begin{array}{l}\text { New Practical } \\
\text { Chinese Reader } \\
\text { (Books III) }\end{array}$ & $\begin{array}{l}\text { Chinese } \\
\text { majors }\end{array}$ \\
\hline Ma & Female & 26 & $\begin{array}{c}\text { International Business } \\
\text { in Russian (Bachelor) } \\
\text { Translation in Russia } \\
\text { (Master) }\end{array}$ & $\begin{array}{l}\text { Chinese } \\
\text { intensive } \\
\text { reading }\end{array}$ & $\begin{array}{l}\text { New Practical } \\
\text { Chinese Reader } \\
\text { (Book II \& III) }\end{array}$ & $\begin{array}{c}\text { Non-Chinese } \\
\text { majors }\end{array}$ \\
\hline Yang & Female & 24 & $\begin{array}{c}\text { International Business } \\
\text { in English (Bachelor) } \\
\text { Translation in English } \\
\text { (Master) }\end{array}$ & $\begin{array}{l}\text { Integrated } \\
\text { Chinese }\end{array}$ & $\begin{array}{c}\text { New Practical } \\
\text { Chinese Reader } \\
\text { (Book II) }\end{array}$ & $\begin{array}{c}\text { Non-Chinese } \\
\text { majors }\end{array}$ \\
\hline
\end{tabular}

Participants Zhang and Li taught Chinese majors to prepare them for the HSK (a test of Chinese-language ability sponsored by Hanban) for their future career development, while the other participants taught students in the $\mathrm{CI}$ who were learning Chinese out of interest. According to the Chinese head of the CI in this study, the adoption of textbooks in CIs involves a two-way approach, whereby the CI headquarters recommends textbooks to CIs all over the world, but CIs themselves also have the autonomy to decide which textbooks to use. Once their applications are ratified, the Office of Textbook Donation at the headquarters will donate textbooks to particular CIs for ten consecutive years. The $\mathrm{CI}$ in this study had received donated textbooks in recent years, i.e., the volumes of New Practical Chinese Reader. Online courses developed by the CI headquarters are also highly recommended, although this $\mathrm{CI}$ did not use them because of insufficient infrastructure.

The first author established connections with all the participants via WeChat, a popular social media app for messages, documents, audio and video calls, allowing regular communication and interviews. The first and third author also joined the participants' WeChat group to observe their daily activities without any interruption.

\subsection{Data Collection}

In the inquiry, we collected data by conducting interviews with the participants, supplemented by gathering artifacts and documents such as the participants' lesson plans, textbooks, school documents, and Hanban's curriculum documents. We also interviewed the Head of the CI to have a holistic view of the administrative and teaching arrangements related to CAL education in the university, from whom we learnt that the participants had the autonomy to choose suitable textbooks for teaching, including those developed and recommended by Hanban.

Since we were not permitted by the university to observe classroom teaching, we conducted extended, semi-structured interviews with the participants, each lasting around $2 \mathrm{~h}$. In the interviews we asked the participants about their prior and current professional and life experiences (see Appendix A). We also asked the participants to evaluate the textbooks they used in teaching. According to McDonough 
et al. [35], questions about textbook evaluation should cover grammar, topics, language skills, structure, exercises, culture etc., in order to explore the participants' attitudes towards the textbooks and their complaints and satisfaction in detail. We also asked our participants to report and explain one unit of teaching to see their engagement with and adaptation of the textbooks and other materials in the planning and delivery of teaching (see Appendix A). All the interviews were conducted in Chinese.

\subsection{Data Analysis}

Informed by relevant theorizations of agency, the first and third authors conducted the data analysis separately. This was to allow a comparison of the process and results of our analyses, especially when differences occurred, and enable further objective discussions with the second author to ensure objectiveness and consistency. First, all the interviews were transcribed verbatim and the transcripts were coded, guided by the research question. Coding was primarily data-driven and thus was conducted inductively, to investigate the identified teachers' engagement with textbooks in relation to their agency orientations under the themes of resistance, appropriation, implementation, approval, and ambivalence as mentioned in the previous section. In the coding process, any emerging codes and themes were double-checked by close examination of the participants' lesson plans and other documents (e.g., textbooks).

After a particular participant's data had been analyzed independently by the first and third authors, the relevant codes and themes related to that participant were compared and contrasted to achieve basic agreement. All the participants' data were analyzed in a similar way. Then, the two authors exchanged, examined, and discussed the codes and themes that resulted from their analyses before reaching final agreement, arbitrated by the second author. Finally, the authors worked out conceptual links among all the identified themes and reached a consensus on what constituted answers to the research question.

Take Zhang, for example. First, the first and third authors both read through all of Zhang's interview transcripts to categorize his engagement with the textbook. In order to confirm which kind of engagement Zhang manifested, we looked for the principles and procedures of adaptation he adopted while teaching one unit. Tomlinson [36] (p. 125) discussed "principles and procedures of adaptation such as deletion, addition, reduction, modification and replacement" in the process of materials adaptation. Deletion refers to the cancelation of information, in contrast to addition, i.e., the provision of new information. Reduction means reducing the amount of information, modification refers to changing the information in either form or content, while replacement refers to the complete removal of old content in favor of the new one. Both the authors found that Zhang used adaptation techniques such as addition, reduction, and deletion. Based on his positive evaluation of the textbooks and his adaptive techniques, the first two authors decided that Zhang's agency orientation in his engagement with the textbook corresponded to appropriation, in that he held a positive view towards the textbook and only used techniques to optimize it to enhance his teaching efficiency.

After that, the first and the third authors spent more time reading the transcripts to look for other factors related to his agency orientation. When they had finished, the second author verified the results, especially where differences occurred. Finally, agreement was reached regarding Zhang's factors, i.e., his pedagogical beliefs, teacher identity, and relationships in the community. Table 2 showcases Zhang's case. The analysis for the other participants followed a similar procedure. 
Table 2. Zhang's engagement with the textbook and agency orientation.

\begin{tabular}{|c|c|}
\hline $\begin{array}{l}\text { Adaptation } \\
\text { techniques }\end{array}$ & $\begin{array}{l}\text { Addition } \\
\text { - } \quad \text { Design vocabulary tasks } \\
\text { - } \quad \text { Give more examples of new characters and words } \\
\text { - } \quad \text { Extend the usage of vocabulary } \\
\text { - } \quad \text { Provide news and videos about Chinese culture } \\
\text { Reduction } \\
\text { - } \quad \text { Ignore some notes already known } \\
\text { - } \quad \text { Reduce some repetitive and mechanical exercises } \\
\text { Deletion } \\
\text { - } \quad \text { Delete the content of literature } \\
\text { General commentary: } \\
\text { - } \quad \text { “There are more advantages than disadvantages." }\end{array}$ \\
\hline $\begin{array}{l}\text { Agency } \\
\text { orientation }\end{array}$ & Appropriation \\
\hline $\begin{array}{l}\text { Factors affecting } \\
\text { teacher agency }\end{array}$ & $\begin{array}{l}\text { Pedagogical practice } \\
\text { - Teach the different sections in the textbook according to his own understanding } \\
\text { Pedagogical beliefs } \\
\text { - "Chinese language teaching should emphasize vocabulary, mainly the differences } \\
\text { - "Tetween synonyms." } \\
\text { - "The purpose of learning language is for communication and examination." } \\
\text { Teacher identity } \\
\text { - "I have a solid foundation in Chinese Language knowledge ... especially in } \\
\text { grammar, synonyms of Chinese characters, language functions." }\end{array}$ \\
\hline
\end{tabular}

\section{Results}

\subsection{CAL Teachers' Engagement with Textbooks and Agency Orientations}

The analysis of the interview data revealed that the participants showed a variety of responses to the textbooks in circulation at the CI. For instance, Li was highly critical of the texts, exercises, and Russian translation in the textbooks. She believed that the information about China was outdated and misleading. She also complained that all the texts in Books II and III were dialogues, which, in her view, was not helpful for students who were practicing writing. Zhang appreciated the textbooks in that the grammar and vocabulary were sequenced appropriately, although with some minor problems such as problematic explanation of particular characters in the notes, a lack of numbering in new word lists, and so on. He also mentioned that Books I to III were better than Books IV and V because the themes in the former were more practical and less theoretical than those in the latter.

$\mathrm{Wu}$ and Ma also shared a similar view, which was that the topics were useful and practical and the vocabulary was scientifically sequenced in Book I. More specifically, Ma thought that Book I was better than Book II in terms of grammar and vocabulary. Yang briefly said that Book I was well organized, although there was not enough vocabulary and some information about Western culture was confusing and misleading. It seems that all the participants felt that the given textbooks for teaching CAL learners had room for adaptation and improvement, and they displayed different orientations in their engagement with the textbooks, which is indicative of their agency. In spite of this, all the participants were very satisfied that each textbook was well equipped with resource packages including audios, videos, students' books, teachers' books, etc., which was convenient for them when they were selecting and adapting materials to meet local needs. 
Summarizing from the participants' interview narratives, in Table 3 we present the identified agency orientations in terms of their engagement with the textbooks for CAL teaching. We will elaborate further on our analysis of the participants' interview narratives below.

Table 3. The participants' agency orientations in their engagement with textbooks.

\begin{tabular}{ll}
\hline Names & Engagement with Textbooks \\
\hline Zhang & appropriation \\
$\mathrm{Li}$ & from appropriation to resistance \\
$\mathrm{Wu}$ & implementation \\
$\mathrm{Ma}$ & from implementation to ambivalence \\
Yang & implementation \\
\hline
\end{tabular}

\subsubsection{Appropriation}

Although Li and Zhang had different opinions of the textbooks, both of them enacted agency of appropriation by trying their best to adapt the textbook to meet their teaching and learning needs. Li mentioned that she provided "new and fresh information" for students several times in her teaching:

I have to prepare my courses every day to look for the current news about China and ask students to read and answer the questions about it. (Li)

Like Li, Zhang also attempted to add additional information to facilitate his teaching in the process of adapting the textbooks for teaching. With a Bachelor's degree in Chinese Language and Literature, Zhang placed emphasis on grammar and vocabulary in his teaching. For this reason, he carefully selected and collected language usage examples from various sources to help to explain the relevant grammatical points and vocabulary:

I won't give a large amount of information, but I will provide some extensive knowledge to elaborate more on vocabulary and grammar. (Zhang)

To illustrate his point, he described how he added more sentence examples to illustrate the usage of “得", a Chinese character frequently used as an adverb, because the textbooks only contained limited sentence examples. Besides grammar and vocabulary, he also used the technique of addition in other aspects such as videos and other materials related to Chinese peoples' mode of thinking and characters, games and quizzes, etc.

It should be noted that both of the participants not only added materials in their teaching based on the textbooks, but also employed the technique of deduction to minimize exercises and tasks in the textbooks that appeared to be repetitive and boring.

\subsubsection{Implementation}

$\mathrm{Wu}, \mathrm{Ma}$, and Yang's engagement with textbooks can be seen as indicating an implementation-oriented agency, but with different emphases. $\mathrm{Wu}$, who highly appreciated the textbook, focused on the most useful and important parts from the textbook without feeling obliged to use others:

I completely follow the textbook ... I use most of the sections in the textbook including texts, new words, grammar and notes. For the exercise section, I used it in the first five units but reduced it because of limited teaching periods later on. Therefore, I just choose the most important exercises because the teaching periods are very limited ... The other section I reduced is the supplementary Chinese characters. I only taught them to write important 
Chinese characters in the texts, and asked them to practice writing the supplementary ones in the textbook after class. $(\mathrm{Wu})$

This extract shows that $\mathrm{Wu}$ used most of the materials from the textbooks, but reduced his use in two sections because limited teaching time forced him to choose the most "useful" sections for CAL learners for everyday communication. Given enough teaching periods, he would have used all the sections. It should be noted that the reason for this choice was based on Wu's positive evaluation of the textbook.

Meanwhile, Ma believed that the textbooks were well organized and met the needs of both teachers and students, even though she complained about the confusing Western cuisine etiquette in the text. She attempted to adapt the textbooks for use in teaching through modification and addition.

For example, in the exercise of "Read the following expressions until you're familiar with them", since there were so many expressions, I asked the students to choose some to read and use others to make sentences. To prevent students from feeling bored of the sentence pattern drills, I didn't ask the students to make sentences with the same sentence patterns. Instead, I asked them to make dialogues with the same patterns. (Ma)

In addition, Ma took the initiative to introduce CAL learners to new apps and materials for learning Chinese, because she was good at using technological tools to facilitate teaching and learning. For instance, she introduced apps such as Hello Chinese and Hanzibao to learn Chinese in order to help her students to learn the strokes of Chinese characters and Pinyin as well. She also encouraged beginner CAL learners to watch Chinese cartoons such as Piggy Peggy to practice the language.

In contrast to implementation via creative efforts like the ones mentioned above, Yang, a new teacher who is a major in neither Chinese nor Russian, implemented the textbook in her teaching without any modifications at the very beginning. She prepared lesson plans for the first four lessons (a total of 12 periods) according to the textbook. After that, she believed she knew how to teach the course content and stopped writing lesson plans. She did not feel the need to add any new information, because she believed that "it will be good enough if they (the students) can learn the content in the textbook". Meanwhile, classroom conditions (e.g., the lack of a projector) also emerged as one of the reasons why she did not add new resources as Ma did. When she was asked how she would deal with a number of inappropriate cultural points noted by the other participants in the inquiry, she responded as follows:

If the students noticed and asked me why, I will explain. Otherwise, I will skip them. (Yang)

It seemed that Yang was limiting her preparations for teaching to what was contained in the textbooks. She did not display the same level of commitment to strengthening the textbooks with additional learning resources, modifications, reductions, or deductions. It could be also contended that Yang's engagement with textbooks in teaching was indicative of a different form of agency as "an emergent phenomenon" [31] (p. 28), through an interplay of personal capacity and the environment via individual acts. However, hidden behind these phenomena of agency orientations are other factors, which will be further analyzed in the following section.

\subsection{Factors Affecting CAL Teachers' Agency Orientations}

By reviewing the interview narratives and reflecting on the wider socio-cultural circumstances, we examined the interplay between teacher agency and other factors. Finally, we identified three factors that may promote or constrain CAL teacher agency, i.e., pedagogical beliefs, teacher identity, and relationships in the community. 


\subsubsection{Pedagogical Beliefs}

Generally speaking, beliefs are "judgments and evaluations we make about ourselves, about others, and about the world around us" [37] (p. 21). Pedagogical beliefs are teachers' ideas about teaching, learning, and assessment etc. Pedagogical beliefs are closely related to teacher agency and teacher work $[30,38]$. Teachers' attitudes, values, and judgments about teaching and learning can shape their pedagogical practices. The five participants expressed different attitudes and feelings towards teaching and learning, and these influenced their practice around the use of textbooks. Table 4 provides a description of the five participants' pedagogical beliefs.

Table 4. The participants' pedagogical beliefs.

\begin{tabular}{cl}
\hline Participants & \multicolumn{1}{c}{ Pedagogical Beliefs } \\
\hline $\mathrm{Li}$ & $\begin{array}{c}\text { "Language learning should be about practical knowledge close to life". } \\
\text { "I want to tell them what a modern China looks like." }\end{array}$ \\
\hline Zhang & $\begin{array}{l}\text { [Chinese language teaching should] "emphasize vocabulary, mainly the differences } \\
\text { between synonyms". } \\
\text { [Chinese majors should learn Chinese for] "communication and examinations". }\end{array}$ \\
\hline $\mathrm{Wu}$ & $\begin{array}{l}\text { I want to "give more speaking opportunities for my students ... to build up their confidence } \\
\text { to speak Chinese". }\end{array}$ \\
\hline $\mathrm{Ma}$ & "It is important for teachers and students to like each other." \\
\hline Yang & "It will be good enough if the students can learn the textbook well." \\
\hline
\end{tabular}

As shown in the table, the five participants had different pedagogical beliefs, even though some of them taught the same kind of students, either Chinese majors or non-majors. Their pedagogical beliefs motivated and determined their teacher behaviours. For instance, Li, dissatisfied with the "outdated content" in the textbook, searched for more up-to-date information such as "four new inventions in China" and other current news stories for her students. Taking a different approach, Zhang focused on knowledge of language by adding more examples of synonym usage when he was using textbook materials in his teaching. For $\mathrm{Wu}$, in order to give more opportunities for students to speak Chinese, he only chose useful and important characters, words, and sentences to explain, and asked students to do more oral practice based on them. He also held speech competitions for students to overcome their stage fright. Ma cared about whether her students liked her teaching or not, and therefore when she was teaching, she was cautious with her students' responses and was ready to make adjustments at any time. Lastly, Yang mainly focused on the textbook content and asked the students do more practice in class.

As noted above, pedagogical beliefs are basically about teaching goals. It is clear that the five participants held various different beliefs as to their teaching goals and content. These beliefs are conceptualized as tacit and unconscious assumptions that influence teachers' behaviours and teaching practices [39]. As a result of their differing beliefs, the participants took different actions aligned with these. Teachers' experience, teaching contexts, and biographies are important factors affecting their behaviors. Take Zhang, for example; as a Chinese major, he believed that his students, who were also Chinese majors, should develop a solid foundation of vocabulary and grammar. This clearly originated from his own learning experiences. For Ma, however, she cared a great deal about forming good relationships with her students, possibly because of her prior experience of being negatively reported by the students. As a whole, we see that pedagogical beliefs, shaped by individuals' interplay with their social process (e.g., prior experiences), have a remarkable influence on teachers' teaching practice.

\subsubsection{Teacher Identity}

Apart from pedagogical beliefs, the data also suggest that the participants demonstrated differences in their practices with textbooks because of differences in their teacher identity. Teacher identity can be 
broadly defined as "the way we make sense of ourselves and the image of ourselves that we present to others" [40] (p. 48), which has a very close relationship with teacher agency. Table 5 shows how the participants saw themselves as teachers.

Table 5. Teacher identity of the five participants.

\begin{tabular}{cl}
\hline Participants & \multicolumn{1}{c}{ Teacher Identity } \\
\hline \multirow{2}{*}{$\mathrm{Li}$} & $\begin{array}{l}\text { "I am very lucky to be a CAL teacher because compared with Chinese majors, I am a layman } \\
\text {.. In order to gain subject knowledge about Chinese, I spent a lot of time reading } \\
\text { extensively and watching instructive videos by myself." }\end{array}$ \\
\hline \multirow{2}{*}{ Zhang } & $\begin{array}{l}\text { "I have a solid foundation in the knowledge of Chinese language ... especially in grammar, } \\
\text { synonyms of Chinese characters, and language functions." }\end{array}$ \\
\hline \multirow{2}{*}{$\mathrm{Wu}$} & $\begin{array}{l}\text { "I learnt not only pedagogical theories but also practical skills of teaching and some talents } \\
\text { about Chinese culture such as paper cutting which CAL teacher candidates from other } \\
\text { universities didn't learn ... I can teach well ... many students choose my course." }\end{array}$ \\
\hline \multirow{2}{*}{$\mathrm{Ma}$} & $\begin{array}{l}\text { "I have confidence in organizing events and activities, and doing administrative work as } \\
\text { well, but I still felt diffident and bewildered when I was faced with problems in teaching." }\end{array}$ \\
\hline \multirow{2}{*}{ Yang } & $\begin{array}{l}\text { "I felt nervous when I started teaching, but later I felt better because I found the teaching } \\
\text { content was simple and easy." }\end{array}$ \\
\hline
\end{tabular}

It is clear that compared with the other participants, both Zhang and Wu considered themselves to be Chinese specialists because they had more professional knowledge about Chinese language teaching than other non-major participants. Zhang expressed a set of well-established pedagogical conceptions about CAL teaching, and expressed reasonable viewpoints about how to use textbooks. Similarly, Wu considered himself a good teacher for two reasons: his educational background, and his popularity among his students. He was proud of his postgraduate education with an emphasis on pedagogy, teaching practice, and Chinese culture. Their confidence in pedagogical content knowledge (PCK) emboldened them to engage with textbooks and make efforts to add to their strengths and minimize the parts that did not fit well with their CAL learners' learning.

In contrast, both $\mathrm{Li}$ and $\mathrm{Ma}$ felt less confident in terms of their professional knowledge, and struggled in their efforts to become qualified CAL teachers. Li made significant efforts to acquire PCK through self-study. For Ma, a non-Chinese major, despite her one-year teaching experience in another Russian-speaking country, she still had no idea how to handle "difficult questions requiring more professional knowledge". The reasons why Yang only experienced a short period of nervousness may be twofold: she had no specific long-term plan compared with other participants, and teaching beginner students was relatively easy.

It may be concluded that the participants with PCK had more confidence in asserting their CAL teacher identities because their relevant professional knowledge enabled them to be more agentive in using textbooks. PCK includes "an understanding of what makes the learning of (a)specific topic easy or difficult: the conceptions and preconceptions that students of different ages and backgrounds bring with them to the learning of those most frequently taught topics and lessons" [41] (p. 9). The two Chinese major participants had sufficient PCK to guide their engagement with textbooks for teaching. However, their non-Chinese-major counterparts appeared to be less assertive about their professionality, although they were still highly committed to their CAL teacher identities. They spared no efforts to undertake self-learning and collaboration in order to acquire additional knowledge about the Chinese language and teaching. The finding meets the research need, as Gong et al. [42] called for more studies about CAL teachers' reflections on their professional development in terms of PCK.

\subsubsection{Relationships in the Community}

Since language teachers' agency-related operations cannot be separated from their social context, the participants' engagement with textbooks in teaching may also be facilitated and constrained by 
their professional relationships in the community. During the inquiry, we noted that shifting contextual conditions mediated the participants' agency and engagement with textbooks.

Both Li and Zhang reported that as yet, there was no well-established syllabus and curriculum in place, since the Chinese language department had only been founded 3 months earlier. Li embraced this as an opportunity to select and develop her own materials, noting that it "gives [her] autonomy to explore which textbook is suitable". During this process she noticed that one of her colleagues had brought a new textbook from China, and after reading it she decided that it was better than the one she was currently using. She subsequently decided to replace her old textbook with the new one.

In contrast, Zhang was apparently much more cautious in selecting textbooks, preferring to work in a safe zone in order to "leave a good impression on the dean". In his teaching he also chose to "teach according to the tradition and my prior experience". We got the impression that Zhang carefully followed the instructions he received from the dean, and believed that he was doing the right thing for his career.

Professional relationships mediated the participants' professional experiences and profoundly influenced their agency-related actions. In the CI, most of the participants were part of a helpful and friendly professional community, wherein they could turn to each other for help if they encountered problems at work. The participants met together to prepare for teaching, and they also spent time together after work. Technology also contributed to the community-building among them, which in turn enhanced their agency in working together to promote their professional development and adopt effective teaching practice. In particular, the use of social media technologies facilitated their exchanges of teaching resources for use in teaching. For instance, Zhang used a video about Chinese culture in his teaching, and shared the video in a virtual community of teachers of which all the participants were members. The video was used by other participants in addition to the textbooks they were already using.

However, the participants' agency-related actions could also be negatively mediated by their professional relationships. For example, Wu was annoyed with his colleagues because he thought they didn't make enough contributions to administrative work. He complained that he was pressurized by a heavy administrative workload, which deprived him of valuable time that he needed to facilitate the effective use of textbooks in teaching.

In summary, the participants' agency-related engagement with textbooks can be mediated by various relations found across the working hierarchy, i.e., the relations between a teacher and their superior, and relations among peers. Trust and expectation from a superior can facilitate an effective engagement with textbooks; friendly working relationships among colleagues can be helpful too, but inequality in the distribution of workload and other aspects may hinder the participants' effective use of textbooks in teaching.

\section{Discussion and Suggestions}

This exploratory inquiry has enabled us to examine the agency of a group of CAL teachers, and the factors affecting it, through their engagement with textbooks in teaching. The analysis of the participants' narrative data helped to reveal a variety of agency orientations in their engagement with textbooks. Further analysis of the data helped us to identify that the participants' agency was "individually varied ... and both socially and individually resourced" [38] (p. 1). The narratives suggest that the participants' engagement with textbooks, seen as indicative of teacher agency, emerged from the interplay between individuals (i.e., beliefs and identity) and contextual processes (e.g., professional relationships) [30]. These findings extend our knowledge of the role of teacher agency in language teachers' efforts to adopt, develop and sustain effective teaching practice [41,43].

This study adds to our understanding of how teacher agency interrelates with diverse sociolinguistic contexts. Although teacher agency has been a popular research topic in the past decade, most research has explored it in EFL contexts. Only a few studies have focused on teachers of LOTEs especially CAL teachers [44]. Our research not only focused on CAL teacher agency in the 
Belarussian context, an underrepresented context in language education research, but also took a closer look at agency orientations and mediating factors (e.g., identity, and community) by focusing on their engagement with textbooks. This enriches our understanding of CAL teacher agency research and the study of teacher agency as a whole with highly situated and contextualized insights. The investigation represents an advancement of CAL teacher agency research, and an encouragement of the research of LOTEs in this field.

Furthermore, the findings emerging from this study, i.e., that pedagogical content knowledge (PCK) can enhance teacher agency, are meaningful for sustaining CAL teachers' professional development for effective teaching. It is noteworthy that the two Chinese majors in this research were significantly more confident than the others, and also, they were expected by the head to teach better. This finding suggests that CAL teachers should have a solid foundation in terms of their PCK, so that they can develop professional pedagogical beliefs and assert desired teacher identity, which underpin and sustain their effective professional practice. To achieve this, pre-service education and in-service training should emphasize the professionalization of CAL teaching and teachers. In light of the findings of this inquiry, material adaptation and development should be regarded as an essential component of CAL teacher preparation and development, as CAL teachers are increasingly called upon to develop tailor-made materials for the specific groups of CAL learners they are expected to teach. As mentioned at the beginning, studies of textbooks in CAL teaching and learning cover a number of topics such as cultural representation [45], readability of texts [46] and so on. Unfortunately, research on material adaptation does not receive much attention in the field of CAL learning and teaching, although some research is available in relation to English language teachers' adaptation of textbooks in teaching [36,47]. Yet, we found in this inquiry that material adaptation and development is a critical part of language teachers' professional practice in a multilingual context. Therefore, we argue that CAL teachers and language teachers need pre-service and in-service development courses designed to help them to adapt and develop pedagogical materials in achieving and sustaining effective professional practice.

Last but not least, it would be desirable for major publishers of CAL textbooks and materials to include frontline CAL teachers as contributors. It is also important for curriculum and textbook developers to prepare a resource package that CAL teachers can use to design or adjust the learning and teaching activities presented in textbooks. The findings also indicate that textbooks that have been developed to help CAL learners to achieve particular curriculum objectives need to be strengthened with language-related activities and resources that are appropriate for language learners in specific contexts.

\section{Conclusions}

So far, the inquiry has advanced our understanding of teacher agency and CAL teachers' professional practice by focusing on their engagement with textbooks in a Belarussian context. However, some limitations must be noted, particularly in that this exploratory inquiry was largely based on teachers' retrospective narratives. We suggest that further research could employ methods of longitudinal inquiry such as ethnography or classroom observation to obtain a clearer picture of CAL teacher agency. Furthermore, the study was restricted to only one context. It is suggested that more studies be needed to find out how CAL teachers develop and sustain their effective professional practice in other contexts. With Chinese becoming an increasingly popular global language, more research should be conducted into CAL teacher agency in diverse learning contexts to achieve this purpose. All in all, we also hope that our findings are helpful in understanding CAL teacher agency, and may also help to develop and sustain the effective professional practice of language teachers, who play a critical role in promoting and sustaining multilingualism in universities globally.

Author Contributions: The three authors contributed collaboratively. W.R. and D.W. conducted the research conceptualization. M.B. and D.W. collectively worked on data collection, analysis, and writing. All authors have read and agreed upon the published version of the manuscript.

Funding: The research was founded by the Jiangsu Planning Office of Philosophy and Social Science (Grant No. 17YYB003), Nanjing, China, obtained by the first author, M.B. 
Acknowledgments: The authors would like to acknowledge the support from the CAL teachers and the head of the Confucius Institute who spared time out of their busy schedules to receive our interviews of several rounds.

Conflicts of Interest: The authors declare no conflict of interest.

\section{Appendix A}

Interview questions:

1. Can you introduce yourself, such as educational background, working experiences, etc.?

2. What are your comments on the textbook as a whole and different sections specifically?

3. What do you think of the organization of the textbook you are using or have used?

4. Can you give an example of how you taught one of the units in the textbook?

5. What do you usually do when you encounter some problems in teaching? Any example?

6. What do you think of yourself as a CAL teacher?

7. How do you get along with your colleagues?

8. What is your career plan for the future?

\section{References}

1. Guo, Q.J.; Tao, J.; Gao, X.S. Language teacher education in System. System 2019, 82, 132-139. [CrossRef]

2. Ricento, T.K.; Hornberger, N.H. Unpeeling the onion: Language planning and policy and the ELT professional. TESOL Q. 1996, 30, 401-427. [CrossRef]

3. Sannino, A. Teachers' talk of experiencing: Conflict, resistance and agency. Teach. Teach. Educ. 2010, 26, 838-844. [CrossRef]

4. Vähäsantanen, K.; Eteläpelto, A. Vocational teachers in the face of a major educational reform: Individual ways of negotiating professional identities. J. Educ. Work. 2009, 22, 15-33. [CrossRef]

5. Wernicke, M. Plurilingualism as agentive resource in L2 teacher identity. System 2018, 79, 91-102. [CrossRef]

6. Miller, E.R.; Kayi-Aydar, H.; Varghese, M.; Vitanova, G. Editors' introduction to interdisciplinarity in language teacher agency: Theoretical and analytical explorations. System 2018, 79, 1-6. [CrossRef]

7. Tao, J.; Gao, X.S. Teacher agency and identity commitment in curricular reform. Teach. Teach. Educ. 2017, 63, 346-355. [CrossRef]

8. Ishihara, N.; Carroll, S.K.; Mahler, D.; Russo, A. Finding a niche in teaching English in Japan: Translingual practice and teacher agency. System 2018, 79, 81-90. [CrossRef]

9. Leal, P.; Crookes, G.V. “Most of my students kept saying, 'I never met a gay person'”: A queer English language teacher's agency for social justice. System 2018, 79, 38-48. [CrossRef]

10. Christiansen, M.S.; Du, Q.; Fang, M.; Hirvela, A. Doctoral students' agency as second language writing teachers: The quest for expertise. System 2018, 79, 19-27. [CrossRef]

11. Benesch, S. Emotions as agency: Feeling rules, emotion labor, and English language teachers' decision-making. System 2018, 79, 60-69. [CrossRef]

12. Marr, T.; English, F. Rethinking TESOL in Diverse Global Settings: The Language and the Teacher in a Time of Change; Bloomsbury: London, UK, 2019.

13. Chen, Y.S.; Ren, W.; Lin, C.Y. English as a Lingua Franca: From theory to practice. Lang. Teach. 2020, 53, 63-80. [CrossRef]

14. Gao, X.S.; Zheng, Y.Y. Multilingualism and higher education in Greater China. J. Multiling. Multicult. Dev. 2019, 40, 555-561. [CrossRef]

15. Han, Y.W.; Gao, X.S.; Xia, J.Y. Problematising recent developments in non-English foreign language education in Chinese universities. J. Multiling. Multicult. Dev. 2019, 40, 562-575. [CrossRef]

16. Guo, Y.D.; Sit, H.; Bao, M. Sustainable Careers of Teachers of Languages Other than English (LOTEs) for Sustainable Multilingualism in Chinese Universities. Sustainability 2020, 12, 6396. [CrossRef]

17. Wang, D.P. Learning or becoming: Ideology and national identity in textbooks for international learners of Chinese. Cogent. Educ. 2016, 3, 1140361. [CrossRef] 
18. Tsang, S.C. An exploratory study of Chinese-as-an-additional-language teachers' agency in post-1997 Hong Kong: An ecological perspective. Curr. Issues Lang. Plan. 2020, 1-22. [CrossRef]

19. Li, C.; Gil, J. Soft Power and the Global Promotion of Chinese Language Learning: The Confucius Institute Project. Lang. Policy. 2019, 18, 159-161. [CrossRef]

20. Hu, X.H. "zài hànyǔrè zhōng zǒuchūqù-jìnniánlái guónèi duìwài hànyu jiàocái chūbăn shùpíng" Finding a way out: A critique of textbooks of Chinese as a foreign language. Chin. Publ. J. 2007, 12, 31-33. (In Chinese)

21. Zhou, X.B.; Bo, W.; Wang, L.; Li, Y.N. "guójì hànyǔ jiàocái yǔliàokù de jiànshè yǔ yìngyòng” A Study of the Construction and Application of the TCSOL Material Corpus. Appl. Linguist. 2017, 1, 125-135. (In Chinese)

22. Li, Q. "hànyǔ jiàocái de "guóbiéhuà" wèntí tàntǎo" On country specialization of Chinese Language Textbooks. Chin. Teach. World. 2015, 4, 526-540. (In Chinese)

23. Song, B.B. Exploring the Cultural Content in Chinese ELT Textbooks from Intercultural Perspectives. J. Asia. TEFL 2019, 16, 267-278. [CrossRef]

24. Curdt-Christiansen, X.L. Reading the World through Words: Cultural Themes in Heritage Chinese Language Textbooks. Lang. Educ. 2008, 2, 95-113. [CrossRef]

25. Ying, Y.; Mursitama, T.N.; Novianti, N. Suitability of Textbook for the Improvement of Linguistic Competence in Chinese by International Relations Students in Indonesia. Pertanika J. Soc. Sci. Humanit. 2018, 3, 1241-1252.

26. Eteläpelto, A.; Vähäsantanen, K.; Hokka, P.; Paloniemi, S. What is agency? Conceptualizing professional agency at work. Educ. Res. Rev. 2013, 10, 45-65. [CrossRef]

27. Giddens, A. The Constitution of Society; University of California Press: Berkley, MI, USA, 1984.

28. Archer, M. Being Human: The Problem of Agency; Cambridge University Press: Cambridge, UK, 2000.

29. Archer, M. Structure, Agency and the Internal Conversation; Cambridge University Press: Cambridge, UK, 2003.

30. Priestley, M.; Biesta, G.; Robinson, S. Teacher Agency: An Ecological Approach; Bloomsbury: London, UK, 2015.

31. Billett, S. Work, subjectivity and learning. In Work, Subjectivity and Learning: Understanding Learning through Working Life; Billett, S., Fenwick, T., Somerville, M., Eds.; Springer: Dordrecht, NL, USA, 2006; pp. 1-20.

32. Emirbayer, M.; Mische, A. What Is Agency? Am. J. Sociol. 1998, 103, 962-1023. [CrossRef]

33. Lasky, S. A sociocultural approach to understanding teacher identity, agency and professional vulnerability in a context of secondary school reform. Teach. Teach. Educ. 2005, 21, 899-916. [CrossRef]

34. Graves, K.; Garton, S. Materials in ELT: Looking ahead. In International Perspectives on Materials in ELT; Garton, S., Graves, K., Eds.; Palgrave Macmillan: Harlow, UK, 2014; pp. 270-279.

35. McDonough, J.; Shaw, C.; Masuhara, H. Materials and Methods in ELT, 3rd ed.; Wiley-Blackwell: Chichester, UK, 2013.

36. Tomlinson, B. The Complete Guide to the Theory and Practice of Materials Development; Wiley: Blackwell, UK, 2018.

37. Yero, J.L. Teaching in Mind: How Teacher Thinking Shapes Education; MindFlight Publishing: Hamilton, MT, USA, 2002.

38. Biesta, G.; Priestley, M.; Robinson, S. The role of beliefs in teacher agency. Teach. Teach. 2015, 21, 624-640. [CrossRef]

39. Kagan, D.M. Implications of research on teacher belief. Educ. Psychol. 1992, 27, 65-90. [CrossRef]

40. Day, C. Uncertain Professional Identities: Managing the Emotional Contexts of Teaching. In New Understandings of Teacher's Work: Emotions and Educational Change; Day, C., Lee, J.C.K., Eds.; Springer: New York, NY, USA, 2011; pp. 45-64.

41. Shulman, L.S. Those who understand: Knowledge growth in teaching. Educ. Res. 1986, 2, 4-14. [CrossRef]

42. Gong, Y.; Gao, X.S.; Lyu, B. Teaching Chinese as a second or foreign language to non-Chinese learners in mainland china (2014-2018). Lang. Teach. 2020, 53, 44-62. [CrossRef]

43. Ren, W.; Han, Z.R. The representation of pragmatic knowledge in recent ELT textbooks. ELT J. 2016, 70, 424-434. [CrossRef]

44. Lai, C.; Li, Z.; Gong, Y. Teacher agency and professional learning in cross-cultural teaching contexts: Accounts of Chinese teachers from international schools in Hong Kong. Teach. Teach. Educ. 2015, 54, 12-21. [CrossRef]

45. Xiong, T.; Peng, Y. Representing culture in Chinese as a second language textbooks: A critical social semiotic approach. Lang. Cult. Curric. 2020, 2, 1-20. [CrossRef] 
46. Soh, K.C. Readability Formula for Chinese as a Second Language: An Exploratory Study. Front. Educ. China. 2019, 14, 551-574. [CrossRef]

47. Curdt-Christiansen, X.L. Striking a balance: Cultural conflicts or cultural adaptation. Eur. J. Appl. Linguist. TEFL 2014, 4, 73-92.

(C) 2020 by the authors. Licensee MDPI, Basel, Switzerland. This article is an open access article distributed under the terms and conditions of the Creative Commons Attribution (CC BY) license (http://creativecommons.org/licenses/by/4.0/). 